\title{
PHYSICAL MATHEMATICAL MODELLING OF DIFFICULT ELEMENTS OF ACROBATIC ROCK-AND-
} ROLL

\author{
Adashevskiy V.M. ${ }^{1}$, Iermakov S.S. ${ }^{2}$, Firsova Iu.Iu. ${ }^{1}$ \\ National technical university "KPI" 1 \\ Kharkov state academy of physical culture ${ }^{2}$
}

\begin{abstract}
Annotation. It is shown directions of biomechanics substantiation of implementation acrobatic rock-and-roll Fus-salto element taking into account concrete physical data of sportsmen. Mathematical model is developed for determination the influence on a quality of implementation of technical element of such parameters as: speed and angle of flight of centre-of-mass sportsman's body, position of centre-of-mass body of sportsman in the initial phases of throw exercises, initial angular velocity of rotation of body of sportsman. It is developed mathematical model to determine the impact on the quality of the technical element parameters such as speed and angle of flight of centre-of-mass of the athlete's body, the position of center-of-mass of the athlete's body in the initial phases of throwing exercises in the initial angular velocity of the athlete's body. The parameters of exposure axial moments of inertia for different groupings of body angular velocity the athlete's body in flight and air resistance forces of environment to flight characteristics of the body. Directions of choice of necessary biomechanics descriptions which are able to realize sportsmen are shown. It is offered recommendations are on the increase of efficiency of implementation of element of acrobatic rock-and-roll of Fus-salto. Keywords: rock-and-roll, biomechanics, trajectory, throw.
\end{abstract}

\section{Introduction}

Acrobatic rock'n'roll belongs to the group of kinds of sports with complex coordination; the content of its technical elements is based on interaction of partners and is presented as motion composition with music accompaniment. The base of rock'n'roll acrobatic elements are: throws, flights and catching of a partners, mutual movements, postures with keeping balance in static and dynamics and so on. One of the most difficult elements is "fussomersault" - non-supported of partner's body with full turnover head, fulfilled by pushing of partner's foot, which she places on his coupled hands, upward. [10, 11, 15]. In this case it seems to be purposeful to use the methods of mathematical simulation in order to obtain optimal bio-mechanical parameters of partners' movements.

Sport result of such difficult element of acrobatic rock'n'roll as "fus-somersault" is determined, mainly, by reasonable bio-mechanical characteristics, which a sportsman/woman can realize and which depend on:

- rush out speed and rush out angle of sportswoman's body masses' center,

- position of partner's body masses in initial phases of throws,

- initial angle speed of partner's body rotation,

-influence of axial moments of inertia with different body grouping on angle speed of partner's body in flight,

- air resistance influence on body flight's characteristics.

These bio-mechanical characteristics, with their reasonable meanings and combinations will permit to fulfill "fus-somersault" on high technical level and for sportsmen - to receive high mark, considering specific physical data of sportsmen.

The theoretical basis of researches of sport movements' bio-mechanical laws are the works by N.A. Bernstein [2], V.M. Zatsiorskiy [7], A.N. Laputin [4, 8].

The demand in construction of models and, then, selecting of the most optimal bio-mechanical parameters of sportsman's movements was mentioned in the works by V.M. Adashevskiy [1, 2, 14 ], S.S. Yuermakov [6, 14], Lin CF. [12], Pengelly F. [13] et al.

With it, the search of optimal combination of kinematical and dynamic parameters of sportsman's movement becomes of great importance [9, 12-14] considering the laws of mechanical energy transmission from link to link [4, 5, 8]. Such approach permits to successfully influence on result of sports activity $[4,8]$. With it, it is recommended to use mathematical models of movements [1, 6, 12-14].

That is why the demand in more specific theoretical and practical researches with the help of mathematical simulation is obvious.

The research has been carried out as per state-financed subject M0501. "Development of innovative and diagnostic methods of leading kinds of preparedness of different qualification and specialization sportsmen" in $2012-$ 2013.

Purpose, tasks of the works, material and methods

The purpose of the work: is determination of main reasonable bio-mechanical characteristics in difficult element of acrobatic rock'n'roll "fus-somersault", considering specific physical abilities of sportsmen/women and composition of recommendations for improvement of technical level and, consequently, referee's evaluation.

Tasks of the work:

- to carry out critical analysis of special literature,

- to compose calculated schema for determination of main reasonable bio-mechanical characteristics: rush out angle of a sportsman/woman body masses center, position of a sportsman/woman body masses center in initial phases of throws, initial angle speed a sportsman/woman body, influence of axial moments of inertia with different body 


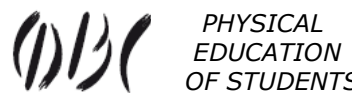

grouping for angle speed of a sportsman/woman body rotation in flight, influence of air resistance on flight characteristics during fulfillment of element of acrobatic rock'n'roll "fus-somersault",

- to compose physico- mathematical model for determination of main, reasonable bio-mechanical characteristics of element of acrobatic rock'n'roll "fus-somersault",

- to determine main bio-mechanical characteristics of body flight by solution of the task of bio mechanical system's dynamics,

- to study bio-mechanical characteristics and obtain them in plotted form,

- to compose recommendations for improvement results of "fus-somersault".

For solution of the tasks we used special program complex "KIDIM", which was developed at department of theoretical mechanics of NTU "KhPI".

Now, let us consider calculated schemas for determination of main reasonable bio-mechanical characteristics in element of acrobatic rock'n'roll "fus-somersault", (fig. 1, 2).

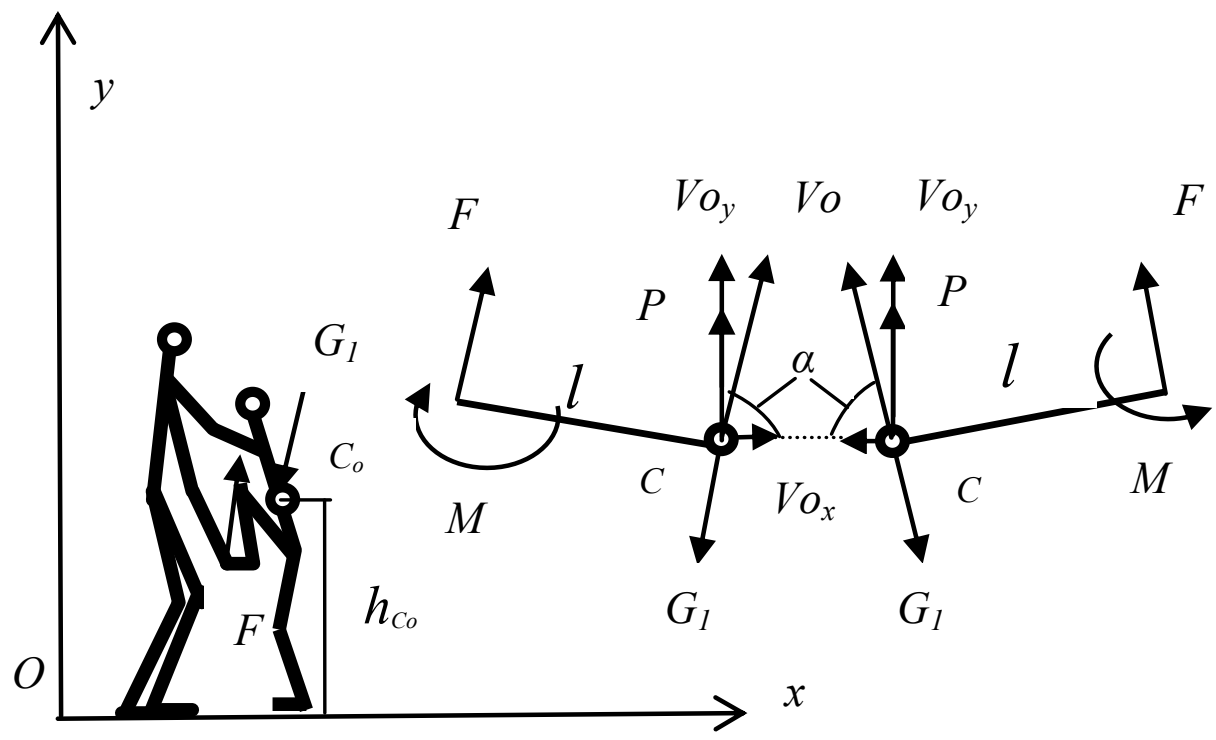

Fig.1. Calculated schema for determination of initial reasonable characteristics of throw

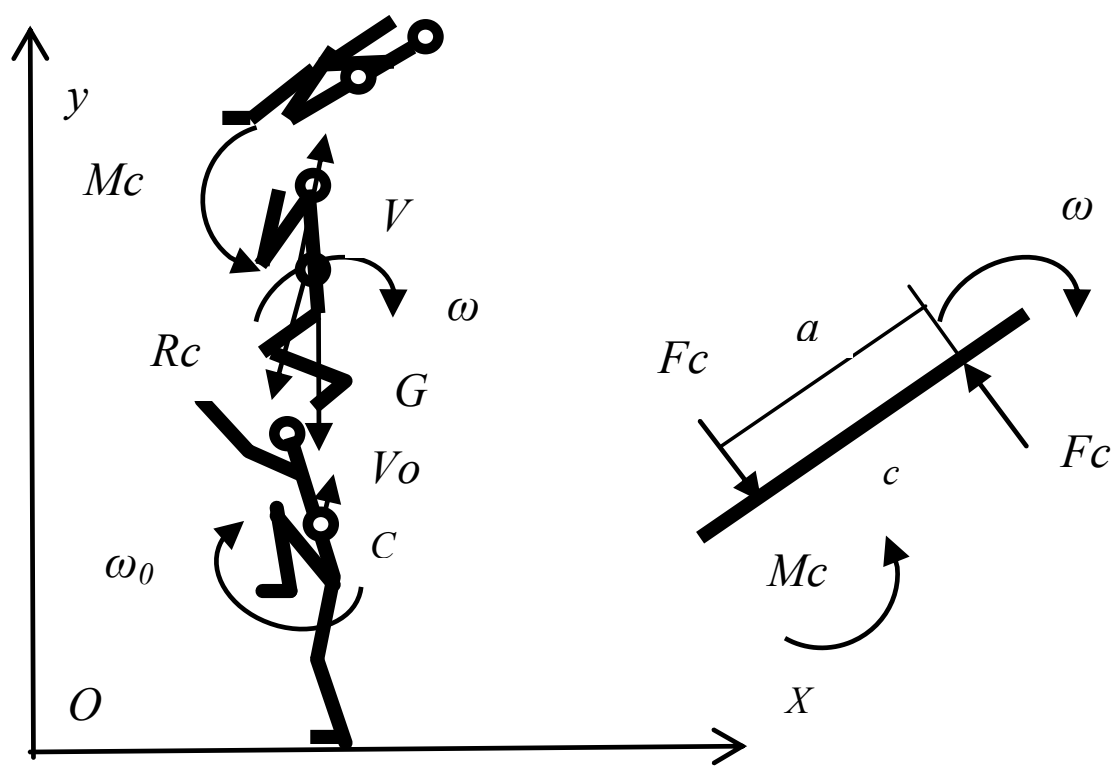

Fig.2. Calculated schema for determination of reasonable bio-mechanical characteristics in flight phase $\mathrm{V}_{0}$ - initial speed of sportsman/woman body masses center's rush out, $\mathrm{Vo}_{\mathrm{X}}-$ projection of body masses center's rush out speed on axis $\mathrm{Ox}$, 
$\mathrm{Vo}_{\mathrm{Y}}$ - projection of body masses center's rush out speed on axis Oy, In projection on Cartesian coordinates system:

$v_{O x}=v_{0} \cos \alpha ; \quad v_{O y}=v_{0} \sin \alpha$

absolute initial speed of rush out

$v_{0}=\sqrt{v_{0 x}^{2}+v_{0 y}^{2}}$

$\mathrm{h}_{\mathrm{C} 0}$ - the height of body masses center at initial time of rush out,

$\sigma_{0}=\sigma-$ angle of body masses center rush out in throw,

$\mathrm{G}$ - gravity force,

$\mathrm{h}_{\mathrm{C}}-$ current height of body masses center,

$\mathrm{Rc}$ - air resistance force,

$\mathrm{Mc}-$ moment of air resistance forces,

where $\mathrm{Mc}=(\mathrm{Fc}) \mathrm{a}$,

for the solution of the set task the force of aerodynamic resistance $R c$ for bodies, which move in air medium with density $\rho$, equals $R_{c}=0.5 \cdot c_{\tau} \rho s V^{2} ; R_{c}=k V^{2} . \mathrm{Fc}-$ is the resultant of distributed forces of air resistance $F_{c}=f V_{\theta p}^{2}=f \omega^{2}(a / 2)^{2}$ or $\quad M_{c}=n \omega^{2}=n \dot{\varphi}^{2}$.

With calculating of these forces dimensionless factors of head resistance $\mathbf{c}_{\tau}$ shall be determined experimentally, depending on the shape of body and its orientation in medium. Value $\mathrm{S}$ (middle) is determined by the value of projection of body cross section on the plane, perpendicular to the axis of movement, $\mathrm{V}$ - absolute speed of body. It is known that air density - $\rho=1,3 \kappa 2 / \mathrm{m}^{3}$. It should be noted that body in flight performs plane-parallel movement. Angle of body turn in sagittal anatomic plane correspondingly change value S. Determination of variable middle $\mathrm{S}$ values and head resistance factor $\mathbf{C}_{\tau}$ requires substantial additional researches, that is why, for solution of the given tasks, we take their averaged values within admissible limits.

Then the values of factors $\mathrm{k}$ and $\mathrm{f}$ :

$\mathrm{k}=0-2 \mathrm{~kg} / \mathrm{m} ; \quad \mathrm{n}=0-0.04 \mathrm{~kg} / \mathrm{m}^{2}$.

As far as in flight phase the sportsman's body moves only in one of anatomic planes - sagittal plane, we can make a system of equations of plane-parallel movement dynamics in projection on axes of coordinates.

$m \ddot{x}_{c}=P_{x}^{e} ; \quad m \ddot{y}_{c}=P_{y}^{e} ; \quad J_{z} \ddot{\varphi}=M_{z}^{e}$.

Where $\mathrm{m}$-mass of body, $\ddot{X}_{c}, \ddot{Y}_{c}$ - correspond to projections of masses center acceleration, $P_{x}^{e}, P_{y}^{e}$ - projections of resultant of external forces, which affect the body $J_{z}$ - moment of inertia in respect to front axis.

$\ddot{\varphi}$ - corresponds to angle acceleration with body turn around front axis, $M_{z}^{e}$ - total moment of external forces of medium resistance in respect to front axis.

With movement in plane $x A y$, the system of equations can be written as follows:

$$
\begin{aligned}
& m \ddot{x}=-R_{c_{X}} ; \quad m \ddot{y}=-G-R_{c_{Y}} J_{z} \ddot{\varphi}=-M_{c} \\
& m \ddot{x}=-k v^{2} \cos \alpha ; \quad m \ddot{y}=-m g-k v^{2} \sin \alpha ; \quad J_{z} \ddot{\varphi}=-n \dot{\varphi}^{2} \\
& \cos \alpha=\dot{x} / v ; \quad \sin \alpha=\dot{y} / v ; \quad v=\sqrt{v_{x}^{2}+v_{y}^{2}}=\sqrt{\dot{x}^{2}+\dot{y}^{2}}
\end{aligned}
$$

$\sigma$ - angle between current projections of speed of body masses center and vector of its speed.

The solution of this task requires integrating of differential equations of movement.

This operation is easily fulfilled with the help of special program complex "KIDIM",w which was developed at department of theoretical mechanics of NTU "KhPI".

Let us determine dependence of main reasonable bio-mechanical characteristics in element of acrobatic rock'n'roll "fus-somersault", considering specific physical characteristics of sportsman/woman, on: rush out speed and angle of body masses center, position of body masses center in initial phases of throws, initial angle speed of body rotation, values of axial moments of inertia with different groupings of body, values of air resistance (see fig. 3-9). 
trajectory: $\mathbf{y}_{\mathbf{1}}\left(\mathbf{x}_{1}\right), \mathbf{y}_{\mathbf{2}}\left(\mathbf{x}_{\mathbf{2}}\right), \mathbf{y}_{\mathbf{3}}\left(\mathbf{x}_{3}\right), \mathbf{y}_{\mathbf{4}}\left(\mathbf{x}_{\mathbf{4}}\right), \mathbf{y}_{\mathbf{5}}\left(\mathbf{x}_{\mathbf{5}}\right)$

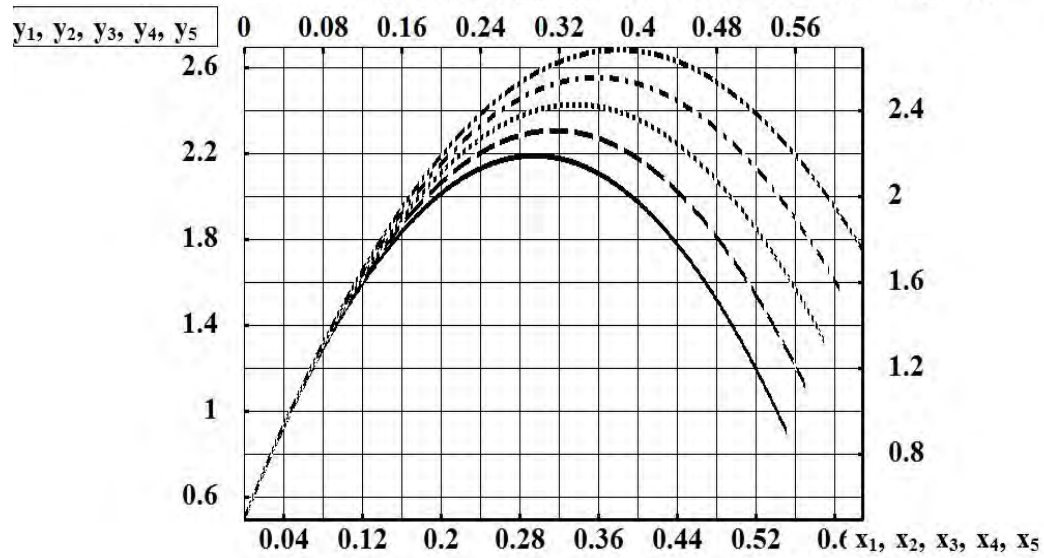

- .. $\mathrm{V}_{0}=6.6 \mathrm{~m} / \mathrm{c} ; \boldsymbol{-} . \mathrm{V}_{0}=6.4 \mathrm{~m} / \mathrm{c} ; \cdots . . \mathrm{V}_{0}=6.2 \mathrm{~m} / \mathrm{c} ; \boldsymbol{-}$ - $\mathrm{V}_{0}=6.0 \mathrm{~m} / \mathrm{c}$;

$\mathrm{V}_{0}=5.8 \mathrm{~m} / \mathrm{c}$.

Fig.3. Characteristic curves of body masses center's trajectory for different values of initial rush out speed.

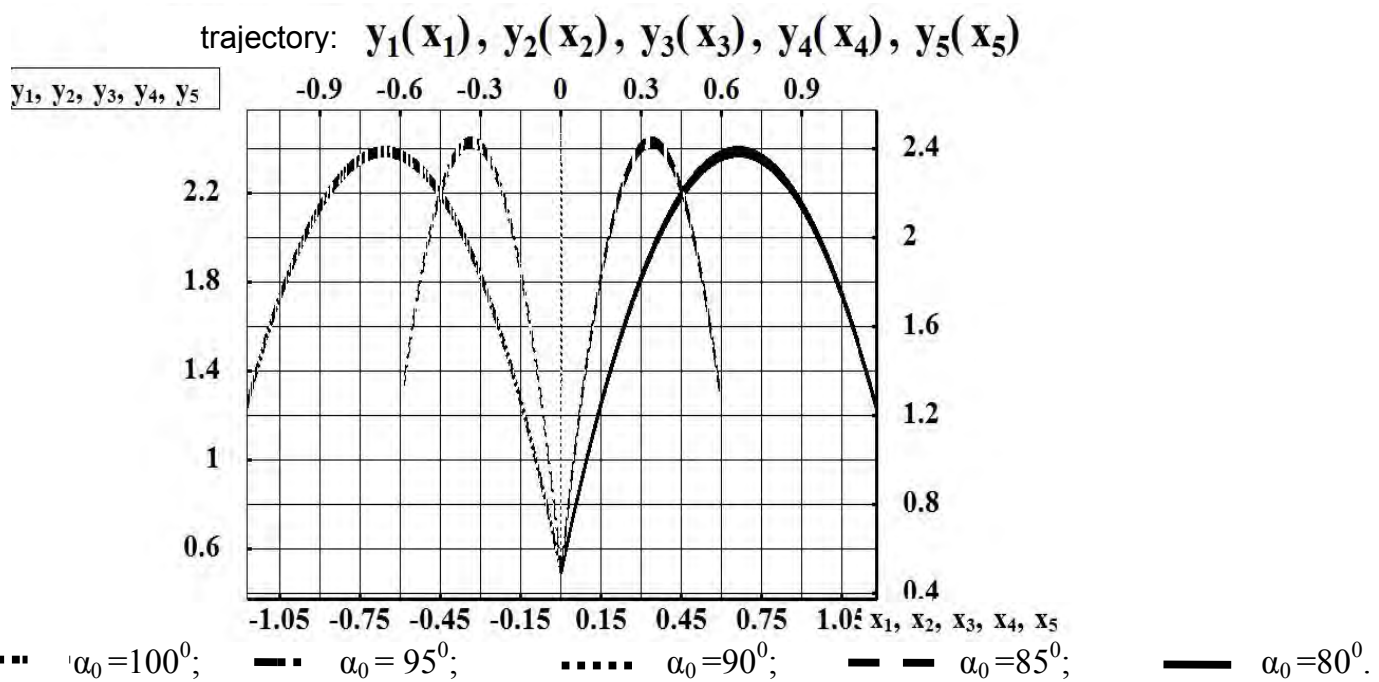

Fig.4. Characteristic curves of body masses center's trajectory for different values of initial rush out angles.

trajectory: $\quad \mathbf{y}_{1}\left(\mathbf{x}_{1}\right), \mathbf{y}_{2}\left(\mathbf{x}_{2}\right), \mathbf{y}_{3}\left(\mathbf{x}_{3}\right), \mathbf{y}_{\mathbf{4}}\left(\mathbf{x}_{4}\right), \mathbf{y}_{5}\left(\mathbf{x}_{5}\right)$

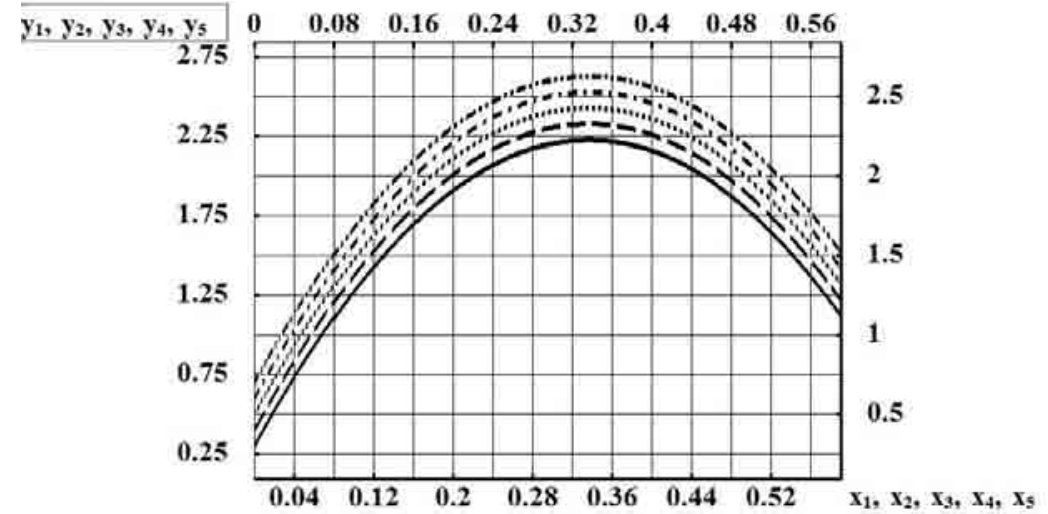

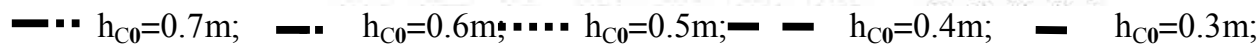

Fig.5. Characteristic curves of body masses center's trajectory for different values of body masses height during throw 
number of revolutions: $\mathbf{N}_{1}, \mathbf{N}_{2}, \mathbf{N}_{3}, \mathbf{N}_{4}, \mathbf{N}_{5}$

$\begin{array}{lllllllll}\mathrm{N}_{1}, \mathrm{~N}_{2}, \mathrm{~N}_{3}, \mathrm{~N}_{4}, \mathrm{~N}_{5} & 0 & 0.15 & 0.3 & 0.45 & 0.6 & 0.75 & 0.9 & 1.05\end{array}$

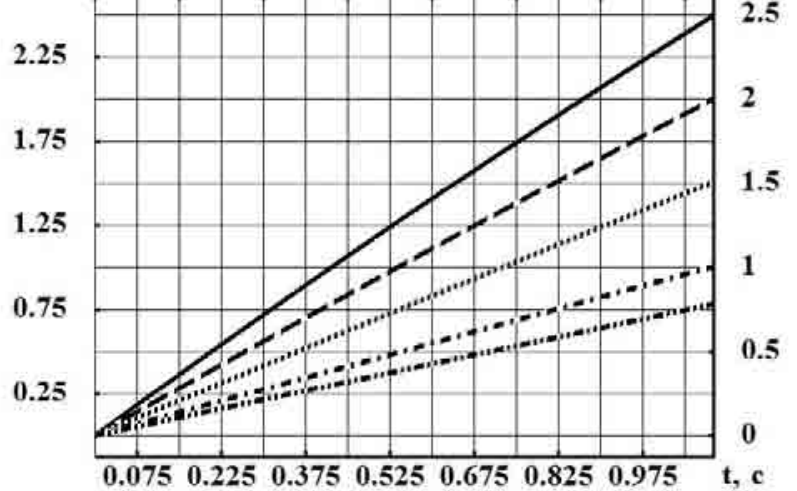

\section{5 \\ 1.5 \\ s.}

$\begin{array}{lllllll}0.075 & 0.225 & 0.375 & 0.525 & 0.675 & 0.825 & 0.975\end{array}$

-.. $\mathrm{I}_{\mathrm{C}}=6 \mathrm{kgm}^{2} ;$ - $\mathrm{I}_{\mathrm{C}}=5 \mathrm{kgm}^{2} ; \ldots \ldots \mathrm{I}_{\mathrm{C}}=4 \mathrm{kgm}^{2} ;$ - $\quad \mathrm{I}_{\mathrm{C}}=3 \mathrm{kgm}^{2} ; \quad$ I $\mathrm{I}_{\mathrm{C}}=2 \mathrm{kgm}^{2}$.

Fig.6. Characteristic curves of quantity of rotations for different values of moments of inertia in respect to front axis

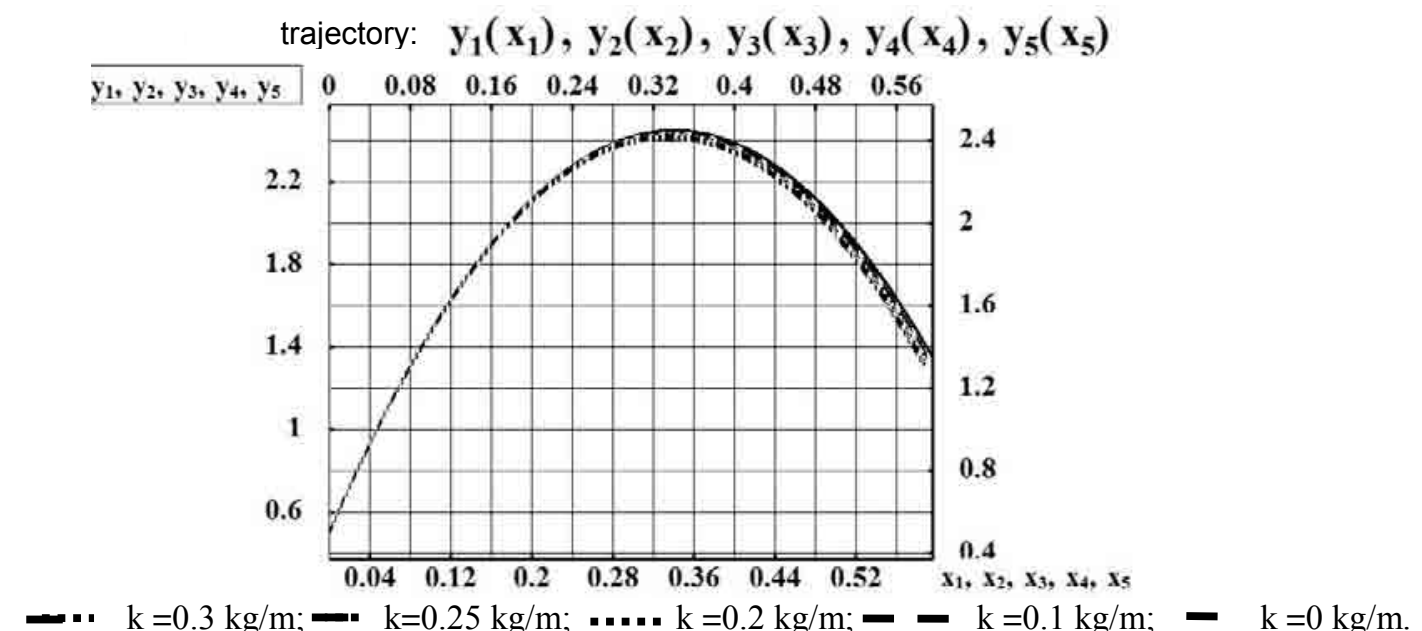

Fig.7. Characteristic curves of body masses center's trajectory for different values of

$$
\text { number of revolutions: } \quad \mathbf{N}_{1}, \mathbf{N}_{2}, \mathbf{N}_{3}, \mathbf{N}_{4}, \mathbf{N}_{5}
$$

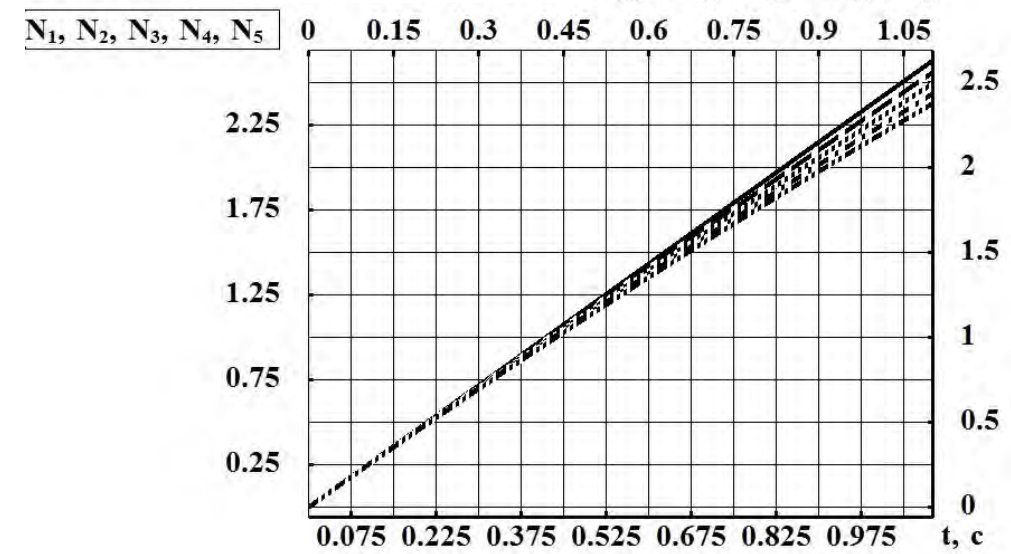

-.. $\mathrm{n}=0.04 \mathrm{kgm}^{2} ;$ - $\mathrm{n}=0.03 \mathrm{kgm}^{2} ; \ldots . \mathrm{n}=0.02 \mathrm{kgm}^{2} ; \quad$ - $\mathrm{n}=0.01 \mathrm{kgm}^{2} ; \quad$ - $\mathrm{n}=0 \mathrm{kgm}^{2}$.

Fig.8. Characteristic curves of quantity of rotations for different values of air resistance factor 


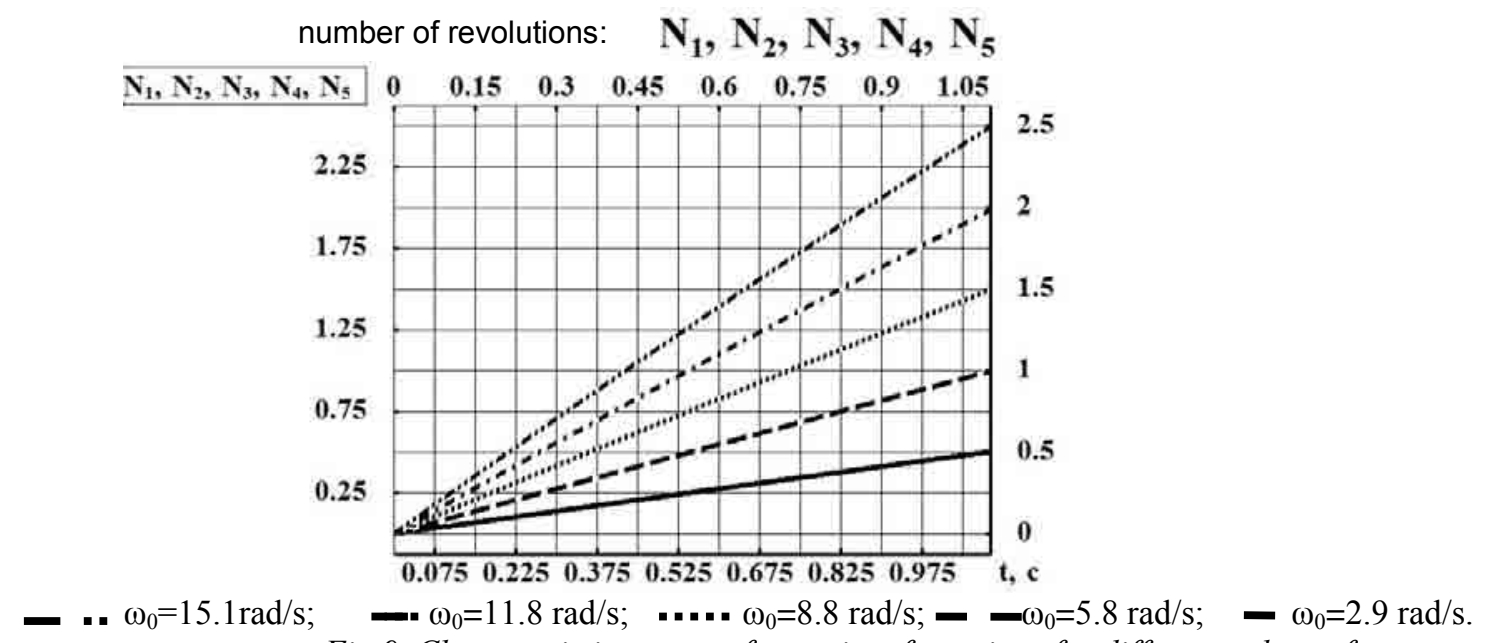

Fig.9. Characteristic curves of quantity of rotations for different values of initial angle speeds of body

Results of calculations of mathematical models and obtained characteristic curves show:

- initial speed and angle of body masses center rush out, position of body masses center in initial phases significantly influence on characteristics of flight (see figs. 3,4),

- masses center trajectories change during throw in average by the same values for different heights of body masses center (see fig. 5),

- different values of moments of inertia of body in respect to front axis substantially change angle speed of body rotation in the flight and, consequently, change the quantity of rotations $\mathrm{N}$, that with reasonable postures can facilitate quicker rotations around front axis (see fig. 6) and even change three times the quantity of rotations $\mathrm{N}$,

- for actual body flight speeds, air resistance exerts little effect on flight characteristics (see figs. 7-8),

- quantity of rotations is in direct proportion to initial angle speed of body (see fig. 9).

\section{Conclusion}

Analysis of the obtained in calculations of characteristics curves results shows that for achievement of high results it is necessary to increase initial speed of rush out, the height of body masses center at rush out, to reduce the moments of inertia, that will facilitate the increase of rotation angle speed in groupings, to reduce angles of body masses center rush out with reasonable combination of the enumerated parameters.

Thus, the plotted characteristics curves permit to improve result with their analysis and further application, considering specific physical features and abilities of sportsmen/women.

\section{References:}

1 Adashevskij V.M. Teoreticheskie osnovy mekhaniki biosistem [Theoretical basis of mechanics of biosystems], Kharkov, KPI Publ., 2001, 260 p.

2 Adashevs'kij V.M. Metrologiia u sporti [Metrology in sport], Kharkov, KPI Publ., 2010, 76 p.

3 Bernshtejn N.A. Ocherki po fiziologii dvizhenij i fiziologii aktivnosti [Essays on physiology of motions and physiology of activity], Moscow, Medicine, 1966, 349 p.

4 Laputin A.M. Biomekhanika sportu [Biomechanics of sport], Kiev, Olympic literature, 2001, 320 p.

5 Buslenko N.P. Modelirovanie slozhnykh sistem [Modeling of complex systems], Moscow, Science, 1988,400 p.

6 Iermakov S.S. Obuchenie tekhnike udarnykh dvizhenij v sportivnykh igrakh na osnove ikh komp'iuternykh modelej i novykh trenazhernykh ustrojstv [Education to the technique of shock motions in sport games on the basis of their computer models and new trainer devices], Dokt. Diss., Kiev, 1997, 47 p.

7 Zaciorskij V.M., Aurin A.S., Seluianov V.N. Biomekhanika dvigatel'nogo apparata cheloveka [Biomechanics of motive vehicle of a man], Moscow, Physical Culture and Sport, 1981, 143 p.

8 Laputin A.N. Obuchenie sportivnym dvizheniiam [Education to sport motions], Kiev, Health, 1986, 216 p.

9 Adouni M., Shirazi-Adl A. Knee joint biomechanics in closed-kinetic-chain exercises. Computer Methods in Biomechanics and Biomedical Engineering. 2009, vol.12(6), pp. 661-670. doi:10.1080/10255840902828375.

10 Frömel K., Stratton G., Vasendova J., Pangrazi R.P. Dance as a Fitness Activity the Impact of Teaching Style and Dance Form. Journal of Physical Education, Recreation \& Dance. 2002, vol.73(5), pp. 26-30. doi:10.1080/07303084.2002.10607805.

11 Li F-X., Margetts S., Fowler I. Use of "chalk" in rock climbing: sine qua non or myth? Journal of Sports Sciences. 2001, vol.19(6), pp. 427-432. doi:10.1080/026404101300149375.

12 Lin C-F., Su F-C., Wu H-W. Ankle biomechanics of ballet Dancers in relevé en pointé dance. Research in Sports Medicine. 2005, vol.13(1), pp. 23-35. doi:10.1080/15438620590922068.

13 Pengelly F. Anatomy for Dance: An Expanded Design. Journal of Dance Education. 2010, vol.10(3), pp. 7782. doi:10.1080/15290824.2010.508696. 
14 Volodymyr Adashevsky, Sergii Iermakov, Krzystof Prusik, Katarzyna Prusik, Karol Gorner. Biomechanics: theory and practice. Gdansk, Zdrowie-Projekt, 2012, 184 p.

15 Waite L. Rock and Roll! Using Classic Rock as a Guide to Fantasy-Theme Analysis. Communication Teacher. 2008, vol.22(1), pp. 10-13. doi:10.1080/17404620801914491.

Information about the authors

Adashevskiy V.M.; adashevsky@ukr.net; National Technical University “KPI”; Frunze str. 21, Kharkov, 61002, Ukraine.

lermakov S.S.: sportart@gmail.com; Kharkov State Academy of Physical Culture; Klochkovskaya str. 99, Kharkov, 61022, Ukraine

Firsova lu.lu.: adashevsky@ukr.net; National Technical University “KPI”; Frunze str. 21, Kharkov, 61002, Ukraine.

Cite this article as: Adashevskiy V.M., Iermakov S.S., Firsova Iu.Iu. Physical mathematical modelling of difficult elements of acrobatic rock-androll. Physical education of students, 2013, vol.3, pp. 3-10. doi:10.6084/m9.figshare.662463

The electronic version of this article is the complete one and can be found online at: http://www.sportpedagogy.org.ua/html/arhive-e.htm

This is an Open Access article distributed under the terms of the Creative Commons Attribution License, which permits unrestricted use, distribution, and reproduction in any medium, provided the original work is properly cited (http://creativecommons.org/licenses/by/3.0/deed.en).

Received: 25.03.2013

Published: 23.04.2013 